\title{
Maximum inspiratory and expiratory pressures in the pre and postoperative periods of patients with incisional abdominal hernia corrected by Lázaro da Silva technique
}

\section{Pressões máximas inspiratórias e expiratórias no pré e pós-operatório de pacientes com hérnias incisionais abdominais corrigidas pela técnica de Lázaro da Silva}

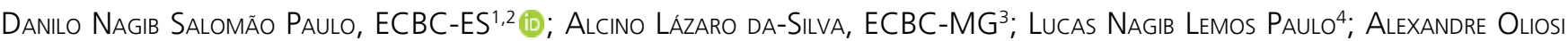
Caliman $^{2}$; Marcela Souza lima Paulo ${ }^{5}$; Matheus Nagib Lemos-Paulo ${ }^{6}$

\section{A B S T R A C T}

\begin{abstract}
Objective: To verify the effect of longitudinal abdominal incisional herniorrhaphy on respiratory muscle pressure. Method: The technique of incisional herniorrhaphy used was proposed by Lázaro da Silva. To measure the pressure, we used a water manometer in 20 patients, median age 48.5 years (range 24 70). We analyzed the maximum inspiratory pressure at the level of residual volume (IP-RV) and functional residual capacity (IP-FRC) and the maximum expiratory pressure of functional residual capacity (EP-FRC) and total lung capacity (EP-TLC) in the preoperative and late postoperative (40 90 days) periods, in 13 patients with large incisional hernias and in 7 patients with medium incisional hernias. Results: There was a significant increase in IP-FRC $(p=0.027)$, IP-RV $(p=0.011)$ and EP-TLC $(p=0.003)$ in patients with large incisional hernias. EP-FRC increased, but not significantly. In patients with medium incisional hernias, the changes were not significant. Conclusion: Surgical correction of large incisional hernias improves the function of the breathing muscles; however, surgery for medium incisional hernias does not alter this function.
\end{abstract}

Keywords: Incisional Hernia. Hernia, Abdominal. Respiratory Muscles. Breath Tests.

\section{INTRODUCTION}

A bdominal incisional hernia is a relatively common surgical disease, with an estimated incidence of around $15-20 \%$ of all laparotomies ${ }^{1}$. Without treatment, it tends to increase progressively and complicate with incarceration ${ }^{2,3}$, obstruction, strangulation ${ }^{4}$, deviation of the lumbar spine with low back pain, skin ulcer, skin infection, hernia rupture ${ }^{2}$, loss of domain ${ }^{5}$, muscle changes $^{6}$, circulatory changes ${ }^{6}$, respiratory failure ${ }^{7}$, and tends to worsen patients' quality of life 8,9 .

Respiratory dysfunction has been attributed to diaphragmatic dysfunction and the lack of normal action of abdominal muscles that are anatomically poorly positioned. When the incisional hernia is corrected, with anatomical restoration of the abdominal wall muscles, diaphragmatic repositioning occurs, with consequent improvement in the function of the breathing muscles.

In an initial study ${ }^{10}$, one of the authors analyzed only the pressure of the breathing muscles at the level of functional residual capacity (volume of air remaining in the lung after normal expiration). The pressures generated by the muscles of the large and medium hernias were not compared, nor were reported the pressures generated from residual volume (volume of air left in the lung after forced expiration) and total lung capacity (maximum volume of air left in the lung after deep inspiration), which can generate other types of results. In view of this issue, we carried out the present study.

The objective was to verify the maximum respiratory pressure in patients with large and medium longitudinal abdominal incisional hernias, before and after surgical correction, in different lung volumes, and the effect of surgery on these pressures.

1 - School of Sciences of Santa Casa de Misericórdia de Vitória, Full Professor of Surgery - Vitória - ES - Brazil 2 - Hospital Santa Casa de Misericórdia de Vitória, Department of General Surgery - Vitória - ES - Brazil 3 - Faculty of Medicine, Federal University of Minas Gerais, Emeritus Professor - Minas Gerais - MG - Brazil 4 - School of Sciences of Santa Casa de Misericórdia de Vitória, Medical School, 11th semester - Vitória - ES - Brazil 5 - School of Sciences of Santa Casa de Misericórdia de Vitória, Assistant Professor - Vitória - ES - Brazil 6 - Hospital Evangélico de Vila Velha - ES, Anesthesiology Service - Vila Velha - ES - Brazil 


\section{METHODS}

After approval by the Ethics Committee of the Higher School of Sciences of Santa Casa de Misericórdia de Vitória, protocol number 3,416,830, we carried out a retrospective study with data obtained from specific medical records. We analyzed 20 patients with longitudinal abdominal incisional hernias, aged between 24 and 70 years (mean $48.50 \pm 14.13$ ). Nine were men, and 11, women, 13 with large incisional hernias (hernia ring $=10 \mathrm{~cm}$ in the transverse axis) and seven with medium incisional hernias (hernia ring $=4-10 \mathrm{~cm}$ in the transverse axis), according to the European Hernia Society ${ }^{11}$. All patients underwent abdominal incisional hernia repair using the Lázaro da Silva technique ${ }^{12}$.

We evaluated the maximum inspiratory pressures at functional residual capacity (IP-FRC) and at residual volume (IP-RV) and the expiratory pressures at functional residual capacity (EP-FRC) and at total lung capacity (EP-TLC). We used a water manometer to measure the pressures in the preoperative and late postoperative periods (40 to 90 days).

The water manometer was described in a previous work ${ }^{10}$, and comprised a plastic collector bottle, with capacity for 5 liters of water, with an upper and a lower opening; a plastic tube approximately $20 \mathrm{~cm}$ long by $1 \mathrm{~cm}$ in diameter, connected to the upper opening of said bottle; at the free end, a disposable tube was attached in which the patient adapted the lips to perform the examination; a long plastic tube with $1 \mathrm{~cm}$ in diameter that came out of the lower opening of the collecting bottle, and was fixed to a $U$ shaped wooden stand, with one vertical branch larger than the other. In the smaller branch, the collecting flask was attached, about $1.35 \mathrm{~m}$ from the soil and the initial portion, descending from the long tube. This was also attached to the horizontal branch and the ascending branch of the wooden stand. The ascending branch graduated in centimeters and, therefore, the long plastic tube was $3.5 \mathrm{~m}$ long, starting from the ground. The ruler graduated in $\mathrm{cm}$ was attached to this tube to read the pressure values (Figure 1).

The water content of the collecting flask was completed until the water column reached zero level, marked on the graduated ruler. Pressures obtained above that level were positive and those below it were negative.
To measure the inspiratory and expiratory pressures, the test was conducted with the following guidelines ${ }^{10}$ : - the patient was keep in an orthostatic position; - the smaller plastic tube with the disposable tube was perfectly adapted to the patient's mouth, to prevent air escape or inflow during the examination; - Next, we instructed the patient to breathe normally and, after maximum expiration, to take forced inspiration. - Hence, the water column descended from zero towards the ground; we thus obtained the inspiratory pressure at residual volume (IP-RV), which we measured at the point where the liquid column remained stable for 1 second, in the long plastic tube.

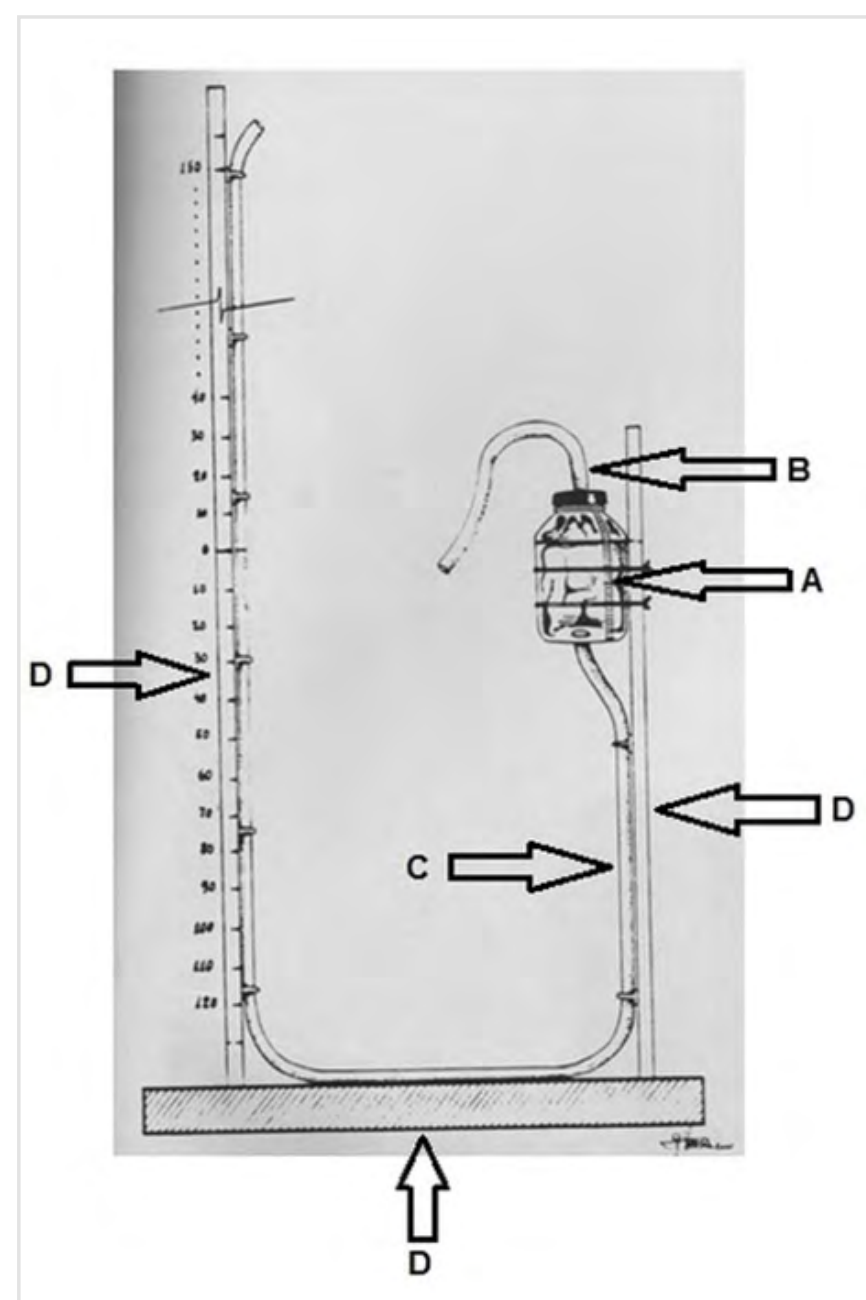

Figure 1. Scheme of the water manometer used to measure the inspiratory and expiratory pressures. A - Water collection bottle with a capacity of 5 liters; $B$ - Tube smaller than $20 \mathrm{~cm}$ where the patient connects the lips in the free part, where a disposable plastic tube is attached for the examination; C - Larger plastic tube, in which water circulates during the examination; $D$ - Wooden stand that fixes the largest plastic tube, in whose ascending portion is fixed the ruler graduated in $\mathrm{cm}$ for reading of the pressure values. 
If after the normal expiration, the patient performed a forced inspiration, we obtained the inspiratory pressure level at functional residual capacity (IP-FRC). If after normal expiration, the patient underwent forced expiration, the pressure obtained was the expiratory pressure at the functional residual capacity (EP-FRC). If the patient performed maximal inspiration and then forced expiration, the pressure obtained was the expiratory pressure at total lung capacity (EP-TLC). To measure the inspiratory pressures, we made a small hole (needle $n^{\circ} 40 / 12$ ) in the smaller plastic tube, to prevent the patient from closing the glottis during the inspiratory procedure. The performance each procedure (IP-RV, IPFRC, EP-FRC, EP-TLC) comprised 10 repetitions, with the same interval between each attempt to allow the patient to.

We repeated the pressure measurements until we obtained values that fulfilled the following criteria ${ }^{10}$ : the efforts were theoretically perfect, that is, there were no leaks and the maximum pressure reached during the maneuver was maintained for at least one second; the two values obtained had, among themselves, a variation of, at most, 10\%; the maximum value obtained was not the last in the series; the individual did not consider himself/herself capable of making a better effort.

We treated the results with the Wilcoxon's nonparametric test for related samples. All tests were twotailed. We considered a value of $p<0.05$ as significant.

\section{RESULTS}

Table 1 and figures 2 and 3 show the variation in the median IP-FRC, IP-RV, EP-FRC and EP-TLC between the preoperative and late postoperative periods among patients with large incisional hernias

Table 2 and figure 2 bring the median IP-FRC, EP-FRC, IP-RV and EP-TLC variations in the same periods amongst patients with medium hernia incisional. We observed a significant increase in IP-RV, IP-FRC and EPTLC between the preoperative and the late postoperative periods in patients with large incisional hernias. In this type of hernia, EP-FRC did not increase significantly. In patients with medium incisional hernias, there were no significant changes between the preoperative and late postoperative moments (Table 2, Figures 2 and 3).
Table 1. Values of maximum respiratory pressures in the preoperative and late postoperative periods of patients with large incisional hernias.

\begin{tabular}{llllllll}
\hline \multicolumn{3}{l}{ Preoperative } & \multicolumn{5}{c}{ Late Postoperative } \\
\hline \multicolumn{3}{c}{ Minimum Maximum } & Median & Minimum & Maximum Median & p-value \\
\hline IP-RV & 65 & 116 & 65 & 90 & 125 & 90 & 0.011 \\
EP-FRC & 30 & 150 & 93 & 45 & 160 & 88 & 0.080 \\
IP-FRC & 33 & 116 & 60 & 21 & 115 & 95 & 0.027 \\
EP-TLC & 32 & 160 & 85 & 52 & 160 & 120 & 0.003
\end{tabular}

IP-RV - Inspiratory pressure at the level of residual volume; EP-FRC Expiratory pressure at the level of functional residual capacity; IP-FRC - Inspiratory pressure at the level of functional residual capacity; EP-TLC - Expiratory pressure at total lung capacity. Wilcoxon's Test. $p \leq 0.05$ significant.

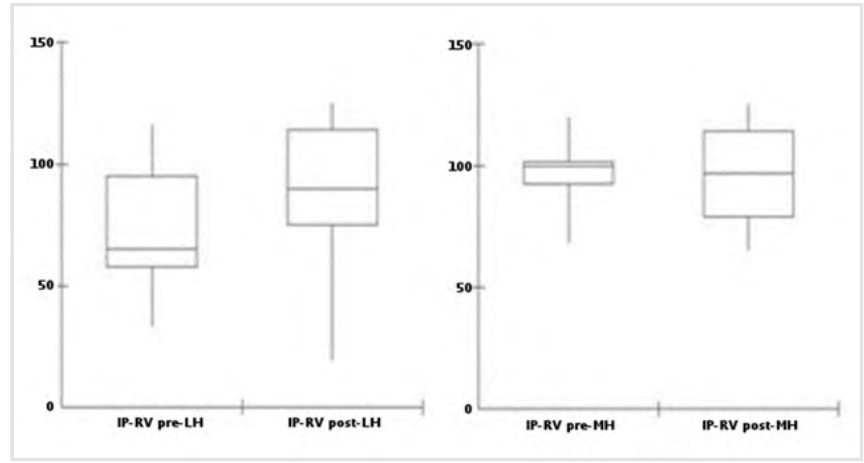

Figure 2. Inspiratory pressure at residual volume (IP-RV) in large and medium hernias. Note that in large hernias (graph on the left) the increase in IP-RV was significant. There was no change in medium hernia cases (graph on the right).

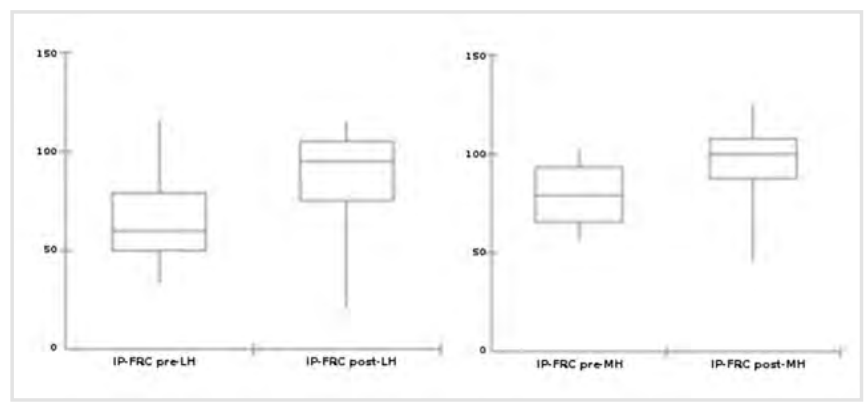

Figure 3. Inspiratory pressure at functional residual capacity in the preoperative (IP-FRC pre $L H$ ) and late postoperative periods (IP-FRC post $L H$ ) of large incisional hernias (left) and in the preoperative (IP-FRC pre MH) and late postoperative periods IP-FRC post $\mathrm{MH}$ ) of medium incisional hernias (right).

Table 2. Values of maximum respiratory pressures in the preoperative and postoperative periods of patients with medium incisional hernias.

\begin{tabular}{lccccccc}
\hline \multicolumn{3}{c}{ Preoperative } & \multicolumn{5}{c}{ Late postoperative } \\
\hline \multicolumn{4}{c}{ Minimum Maximum } & Median & Minimum Maximum & Median p-value \\
\hline IP-RV & 68 & 120 & 100 & 65 & 125 & 97 & 0.83 \\
EP-FRC & 55 & 160 & 104 & 55 & 160 & 110 & 0.22 \\
\hline
\end{tabular}




\begin{tabular}{llllllll}
\hline IP-FRC & 55 & 102 & 79 & 45 & 125 & 100 & 0.09 \\
EP-TLC & 84 & 170 & 125 & 70 & 170 & 125 & 0.60 \\
\hline IP-RV - Inspiratory pressure at the level of residual volume; & EP-FRC - \\
Expiratory pressure at the level of functional residual capacity; IP-FRC \\
- Inspiratory pressure at the level of functional residual capacity; EP-TLC \\
- Expiratory pressure at total lung capacity. Wilcoxon's Test. $p \leq 0.05-$ \\
significant.
\end{tabular}

\section{DISCUSSION}

Unlike spirometry, which analyzes lung volume and flows, manometry analyzes the pressure generated by the respiratory muscles. Theoretically, the greater the pressure generated by the respiratory muscles, the greater the lung volume and flows, as long as there is no respiratory obstruction or any other factor that might interfere in this correlation. This is a fact that needs scientific proof with a good level of evidence.

This study evaluated the respiratory pressures with a water manometer. The technical realization of pressure tests with it has already been described ${ }^{10}$. Although it looks like a rudimentary device, it is reliable in the measurements as long as there is no obstruction or leakage of the tubes. It is even used to calibrate other types of manometers ${ }^{13}$.

The examination on this manometer is easily assimilated by the patient and reproducible. Until the performance of this research, there were no reports on assessment of inspiratory pressures at residual volume and expiratory pressure at total lung capacity in the preoperative and postoperative periods of patients with large and medium incisional hernias.

We observed that the respiratory pressures assessed at different lung volumes in patients with large incisional hernias showed an increase from the preoperative to the late postoperative periods. As demonstrated, there was a significant improvement in IP-FRC, IP-RV and EP-TLC. This could be explained by the fact that in large incisional hernias there is greater distance from the abdominal muscles to the midline, and these muscles may even be altered by previous surgery. This fact hinders the action of such muscles, which start to generate less pressure.

After surgical correction, with the physiological repositioning of these muscles, they start to generate greater pressure, as demonstrated by the increase in EP-FRC $(p=0.08)$ and EP-TLC $(p=0.003)$ in the late postoperative period. The significant increase in EP-TLC observed in this study is in accordance with the result reported by Jensen et al., who observed, after 1 year of surgical correction of incisional hernia, a significant improvement in the maximum expiratory pressure ${ }^{14}$.

It is important to remember that the herniorrhaphy technique used in this work was proposed by Lázaro da Silva, one of whose advantages is the restoration of the linea alba ${ }^{10,12}$, which is associated with improved abdominal wall function. The analysis of the function of the rectus muscle with the dynamometer showed a significant improvement in isokinetic and isometric measurements, all of which were associated with improved quality of life ${ }^{15}$.

We should note that in large incisional hernias, there is also a lowering of the diaphragm and a decrease in the area of apposition of this muscle, which prevents it from exercising its normal action ${ }^{10}$. Similarly, in large incisional hernias, there have been reports of diaphragmatic dysfunction, proven by abdominal ultrasound, which improves with abdominal bandaging and the consequent reinstatement of the visceral content to the abdominal cavity ${ }^{16}$. With surgery, the repositioned diaphragm starts to exert greater inspiratory force, which we observed in this study with the significant increase in IP-FRC and IP-RV. Considering the diaphragm as the primary muscle of inspiration, it was not surprising that the IP-RV and IP-FRC were low in patients with incisional hernia, increasing after surgical correction.

In this work, the respiratory pressures assessed in patients with medium incisional hernias did not display significant variations. This can be verified by the nonalteration of the IP-RV, EP-FRC, IP-FRC and EP-TLC from the preoperative to the late postoperative periods. It is thought that in middle incisional hernias there is no significant subversion of the anatomy of the inspiration and exhalation muscles. Thus, the respiratory pressure generated by these muscles does not drop as much in patients with medium hernias, and the increase in these pressures after surgery would not be as pronounced as in large incisional hernias. This seems to explain why the variation in such pressures was not significant.

It is important to remember that surgical 
correction with improved breathing muscle function also improves respiratory function in terms of ventilation. This could prevent lung diseases due to poor lung ventilation.

This study has limitations. Among these, we can mention the limited sample. To circumvent this issue, we used a non-parametric test for small samples. Despite this limitation, the variations in respiratory pressures in patients with large hernias were significant. Studies with larger samples could confirm the results. A second limitation was the use of the water manometer, criticized by some surgeons for being a rustic, not usually used, device, but it provides reliable results, as noted. The third limitation is that the postoperative assessment in the other studies was performed after 30 days. In this study, we carried out the examinations at least 40 days and at most 90 days after herniorrhaphy. This difference in examination time could bias results, since the recovery of the abdominal wall could vary between 40 and 90 days. A final question is whether the results of this study persist in the long term, and which variables may interfere with them.

\section{CONCLUSION}

Surgical correction of large incisional hernias improves the function of breathing muscles. However, surgery for medium incisional hernia does not alter this function.

\title{
R E S U M O
}

\begin{abstract}
Objetivo: verificar o efeito da herniorrafia incisional abdominal longitudinal na pressão dos músculos da respiração. Método: a técnica de herniorrafia incisional utilizada foi a proposta por Lázaro da Silva. Para aferir a pressão foi utilizado manômetro de água, em 20 pacientes, idade mediana 48,5 anos (mínimo 24, máximo 70). Foram analisadas a pressão máxima inspiratória no nível do volume residual (PIVR) e da capacidade residual funcional (PICRF) e a pressão máxima expiratória da capacidade residual funcional (PECRF) e da capacidade pulmonar total (PECPT), no pré-operatório e pós-operatório tardio (entre 40 e 90 dias), em 13 pacientes com hérnias incisionais grandes e em 7 pacientes com hérnias incisionais médias. Resultados: houve aumento significante da PICRF ( $p=0.027)$, da PIVR $(p=0.011)$, da PECPT ( $p=0.003)$ nos pacientes com hérnias incisionais grandes. A PECRF aumentou, porém de forma não significante. Nos pacientes com hérnias incisionais médias as alterações não foram significantes. Conclusão: a correção cirúrgica da hérnia incisional grande melhora a função dos músculos da respiração, porém a cirurgia da hérnia incisional média não altera a referida função.
\end{abstract}

Palavras chave: Hérnia Incisional. Hérnia Abdominal. Músculos Respiratórios. Testes Respiratórios.

\section{REFERENCES}

1. Hernández-Granados P, López-Cano M, MoralesConde S, Muysoms F, García-Alamino J, PereiraRodríguez JA. Incisional hernia prevention and use of mesh. A narrative review. Cir Esp. 2018;96(2):7687.

2. Emegoakor C, Dike E, Emegoakor F. Unusual complications of incisional hernia. Ann Med Health Sci Res. 2014;4(6):971-4.

3. Azin A, Hirpara $D$, Jackson $T$, Okrainec A, Elnahas A, Chaldi SA, et al. Emergency laparoscopic and open repair of incarcerated ventral hernias: a multiinstitutional comparative analysis with coarsened exact matching. Surg Endosc. 2019;33(9):2812-20.

4. Pandey $H$, Thakur DS, Somashekar $U$, Kothari R, Agarwal P, Sharma D. Use of polypropylene mesh in contaminated and dirty strangulated hernias: short- term results. Hernia. 2018;22(6):1045-50.

5. Bueno-Lledó J, Torregrosa A, Jiménez R, García Pastor P. Preoperative combination of progressive pneumoperitoneum and botulinum toxin type $A$ in patients with loss of domain hernia. Surg Endosc. 2018;32(8):3599-608.

6. Stoppa R, Henry X, Canarelli JP, Largueche S, Verhaeghe $P, A$ bet $D$, et al. Les indications de méthods opératoires selectionnée dans le traitement des venetrations post-operatoires de la paroi abdominale antero-laterále. Propositions sur une serie de 326 observations. Chirurgie. 1979;105(4):276-86.

7. Rives J, Lardennois B, Pire JC, Hibon J. Les grandes éventrations. Importance du volet abdominale et des troubles respiratoires qui lui sont secondaires. Chirurgie. 1973;99(8):547-63.

8. Dietz UA, Menzel S, Lock J, Wiegering A. The treatment of incisional hernia. Dtsch Arztebl Int. 
2018;115(3):31-7. Erratum in: Dtsch Arztebl Int. 2018;115(6):98.

9. Chung L, O'Dwyer PJ. Pain and its effects on physical activity and quality of life before operation in patients undergoing elective inguinal and ventral hernia repair. Am J Surg. 2014;208(3):406-11.

10. Paulo DNS. Repercussões respiratórias funcionais do tratamento da hérnia incisional abdominal longitudinal pela técnica da Transposição peritônioaponeurótica longitudinal bilateral [dissertação]. Belo Horizonte (MG): Universidade Federal de Minas Gerais; 1993.

11. Muysoms FE, Miserez M, Berrevoet F, Campanelli G, Champault GG, Chelala E, et al. Classification of primary and incisional abdominal wall hernias. Hernia. 2009;13(4):407-14.

12. Silva AL, Vieira RG, Anjos GC. Recidivation of bilateral longitudinal peritoneum-aponeurotic transposition on incisional hernioplasty. Arq Gastroenterol. 2004;41(2):134-6.

13. Jardim JRB. Respiratory muscle. Rev Hosp Sao Paulo. 1989:1:101-12.

14. Jensen KK, Backer $\vee$, Jorgensen LN. Abdominal wall reconstruction for large incisional hernia restores expiratory lung function. Surgery. 2017;161(2):51724.

15. Criss CN, Petro CC, Krpata DM, Scafler CM, Lai $\mathrm{N}$, Fiutem J, et al. Functional abdominal wall reconstruction improves core physiology and qualityof-life. Surgery. 2014;156(1):176-82.

16. Koo P, Gartman EJ, Sethi JM, McCool FD. Physiology in Medicine: physiological basis of diaphragmatic dysfunction with abdominal hernias-implications for therapy. J Appl Physiol (1985). 2015;118(2):142-7
Received in: 04/12/2019

Accepted for publication: 02/03/2020

Conflict of interest: no.

Funding source: none.

\section{Mailing address:}

Alexandre Oliosi Caliman

E-mail: caliman.alexandre@gmail.com

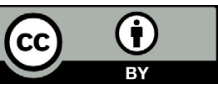

